06

\title{
Эволюция многостенных углеродных нанотрубок и гибридных наноструктур на их основе в процессе получения алюмоматричных композиционных материалов
}

\author{
(C) А.В. Аборкин ${ }^{1}$, К.С. Хорьков ${ }^{1}$, А.М. Объедков ${ }^{2}$, К.В. Кремлев ${ }^{2}$, А.Ю. Изобелло ${ }^{3}$, \\ А.Т. Волочко ${ }^{3}$, М.И. Алымов ${ }^{4}$ \\ ${ }^{1}$ Владимирский государственный университет им. А.Г. и Н.Г. Столетовых, \\ Владимир, Россия \\ ${ }^{2}$ Институт металлоорганической химии им. Г.А. Разуваева РАН, \\ Нижний Новгород, Россия \\ ${ }^{3}$ Физико-технический институт НАН Беларуси, \\ Минск, Беларусь \\ ${ }^{4}$ Институт структурной макрокинетики и проблем материаловедения им. А.Г. Мержанова РАН, \\ Черноголовка, Московская обл., Россия \\ E-mail: aborkin@vlsu.ru
}

Поступило в Редакцию 11 октября 2018 г.

Методом порошковой металлургии получены композиционные материалы на основе алюминиевого сплава АМг2, упрочненные 0.05 wt.\% многостенных углеродных нанотрубок (МУНТ) и А1/МУНТ. С помощью спектроскопии комбинационного рассеяния света изучена эволюция МУНТ и МУНТ-гибридных наноструктур на различных стадиях получения порошковых композитов. Установлено, что для МУНТ-гибридного наполнителя характерны меньшие повреждение и образование фазы $\mathrm{Al}_{4} \mathrm{C}_{3}$ при изотермической выдержке в ходе консолидации, чем в случае исходных МУНТ.

DOI: 10.21883/PJTF.2019.02.47217.17556

В течение двух последних десятилетий в мировой научно-технической литературе опубликованы результаты большого количества исследований, направленных на разработку алюмоматричных композитов, упрочненных многостенными углеродными нанотрубками (МУНТ), которые могут найти применение в авиа- и автомобилестроении. При этом обработка порошковой смеси в шаровых мельницах является одним из наиболее часто используемых методов получения композиционных порошков для последующей консолидации различными методами.

К основным проблемам, с которыми столкнулось большинство исследователей при получении алюмоматричных композиционных материалов, упрочненных МУНТ, следует отнести, с одной стороны, агломерирование МУНТ, а с другой - уменьшение их длины и разрушение $s p^{2}$-связи С-C при высокоэнергетическом воздействии мелющих тел [1]. Еще одна проблема состоит в слабой связи между МУНТ и матрицей. При этом для механической блокировки МУНТ в матричном материале, способствующей увеличению сопротивления разрушению композита при действии растягивающих напряжений, необходимо наличие развитой геометрии на наружной поверхности МУНТ для эффективного переноса и распределения нагрузки [2,3]. С другой стороны, развитая геометрия может появиться лишь в случае дефектов на поверхности МУНТ, наличие которых способствует химическому взаимодействию с матричным материалом и образованию интерфейса из
$\mathrm{Al}_{4} \mathrm{C}_{3}$ [4], снижающего пластичность композиционного материала [5].

Одним из методов контроля повреждения МУНТ при обработке в высокоэнергетической мельнице, оценки равномерности распределения наполнителя и степени образования фазы $\mathrm{Al}_{4} \mathrm{C}_{3}$ является спектроскопия комбинационного рассеяния (КР) света $[6,7]$.

Цель настоящей работы состоит в исследовании и сравнительном анализе эволюции МУНТ и МУНТ-гибридных наноструктур на различных стадиях процесса получения композиционных материалов на основе алюминия методом порошковой металлургии.

Исходная шихта представляла собой гранулы глобулярной формы диаметром 1-2 mm из алюминиевого сплава АМг2 с добавлением 0.05 wt.\% МУНТ или Al/МУНТ. Синтез МУНТ проводился с использованием технологии MOCVD (metalorganic chemical vapour deposition) на лабораторной установке оригинальной конструкции. Осаждение наночастиц алюминия на поверхность МУНТ осуществлялось в горизонтальном кварцевом реакторе с постоянной откачкой продуктов пиролиза. В качестве прекурсора использовался триизобутилалюминий [8]. Механическая обработка исходной шихты была проведена в планетарной мельнице (Fritsch Pulverisette 6) [9]. Консолидация полученного порошка выполнена методом спекания под давлением при температуре $450^{\circ} \mathrm{C}$, давлении $600 \mathrm{MPa}$ и времени выдержки под давлением $30 \mathrm{~min}$.

На рис. 1 представлены полученные с помощью сканирующей электронной микроскопии $(\mathrm{CЭM})$ изображения 
$a$

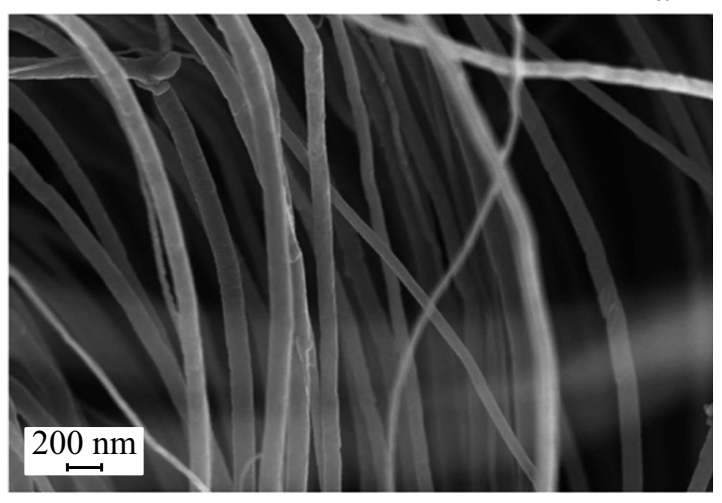

$b$

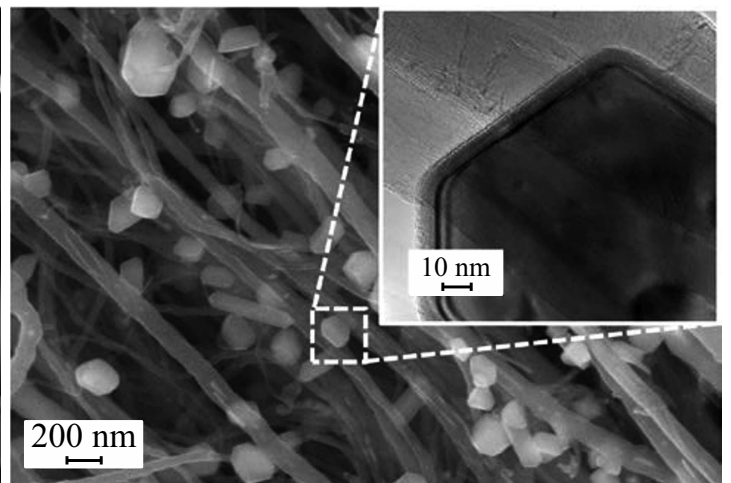

Рис. 1. СЭМ-изображения МУНТ (a) и $\mathrm{Al} / \mathrm{MУНТ} \mathrm{(b).}$

(Carl Zeiss SUPRA 50 VP) исходных МУНT (a) и МУНТ-гибридных наноструктур $(b)$, а также полученное методом просвечивающей электронной микроскопии высокого разрешения изображение (Carl Zeiss LIBRA 200MC) Al/МУНТ (вставка на рис. $1, b$ ).

Из рис. 1, $a$ видно, что исходные МУНТ довольно однородны (внешний диаметр $\sim 70 \mathrm{~nm}$ ). Изучение МУНТ-гибридных наноструктур (рис. $1, b$ ) показало, что наночастицы алюминия на поверхности МУНТ дистанционно разделены и не имеют склонности к образованию агломератов или кластеров [8].

Гранулометрический, структурно-фазовый состав и морфология механически синтезированных композиционных порошков охарактеризованы в работе [10].

На рис. 2 представлены типичные спектры КР (NTEGRA Spectra), полученные для исходных наполнителей (кривые 1 и 2), механически синтезированных композиционных порошков (кривые 3 и 4) и консолидированных образцов (кривые 5 и 6 ).

На спектрах КР наполнителей отчетливо фиксируются $D-, G$ - и $2 D$-полосы углерода, расположенные при 1365 , 1580 и $2720 \mathrm{~cm}^{-1}$. Соотношение интенсивностей $D$ - и $G$-полос, характеризующее степень дефектности исходных наполнителей, составляет $I_{D} / I_{G} \sim 0.25$ и $\sim 0.26$ для МУНТ и $\mathrm{Al} / \mathrm{MУНТ} \mathrm{соответственно.}$

Для спектров КР композиционных порошков характерно повышение интенсивности $D$-полосы, свидетельствующее о повреждении МУНТ и Al/МУНТ, вызванном высокоэнергетическим воздействием мелющих тел. При этом соотношения $I_{D} / I_{G}$ увеличиваются до $\sim 0.95$ и $\sim 0.91$ соответственно. Также происходит значительное уменьшение интенсивности $2 D$-полосы. Кроме того, можно отметить наличие плато при $600-900 \mathrm{~cm}^{-1}$ [11].

Анализ спектров КР консолидированных образцов показывает наличие четко выраженных пиков $\mathrm{Al}_{4} \mathrm{C}_{3}$, расположенных при 857 и $452 \mathrm{~cm}^{-1}$. Таким образом, в процессе изотермической выдержки при консолидации происходит образование кристаллической фазы $\mathrm{Al}_{4} \mathrm{C}_{3}$ в образцах, упрочненных как МУНТ, так и Аl/МУНТ.

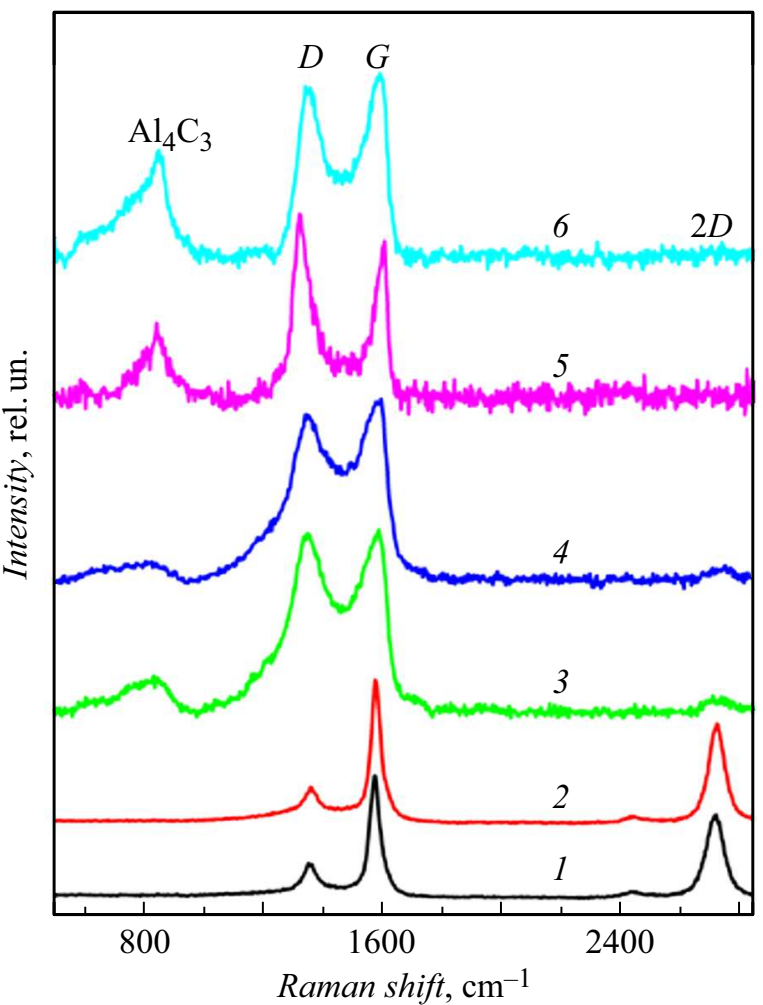

Рис. 2. Результаты спектроскопии КР света. Цифрами обозначены спектры: 1 - МУНТ, 2 - Аl/МУНТ, 3 - порошок АМг $2+0.05$ wt.\% МУНТ, 4 - порошок АМг $2+0.05$ wt.\% Al/MУНТ, 5 - консолидированный образец АМг2 + 0.05 wt.\% МУНТ, 6 - консолидированный образец АМг $2+0.05$ wt.\% Al/MУHT.

Оценка равномерности распределения наполнителя в матричном материале, степени его поврежденности и доли образования фазы $\mathrm{Al}_{4} \mathrm{C}_{3}$ проводилась с помощью линейного микрокартирования на консолидированных образцах. На рис. 3 показаны типичные результаты, иллюстрирующие отношение интенсивностей КР-пиков по длине участка микрокартирования. 

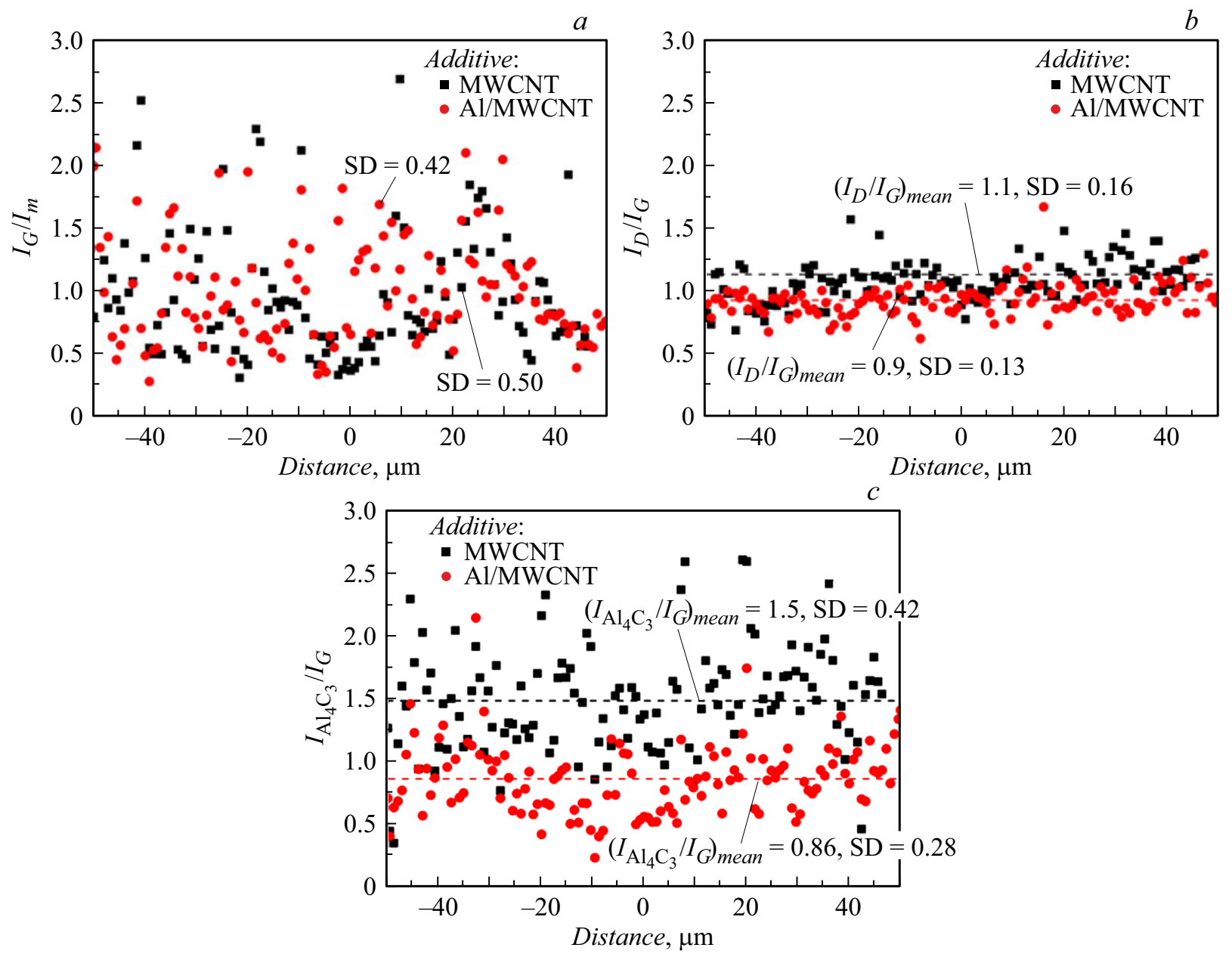

Рис. 3. Результаты микрокартирования, характеризующие равномерность распределения $(a)$ и степень повреждения (b) наполнителя, а также долю образования фазы $\mathrm{Al}_{4} \mathrm{C}_{3}(c)$.

Сравнение отношений интенсивности $G$-пика к интенсивности фона матричного материала $I_{m}$ для консолидированных образцов, упрочненных МУНТ и Аl/МУНТ, характеризующих равномерность распределения наполнителя в матричном материале, показывает незначительное различие между изучаемыми образцами (рис. $3, a$ ). Оценку поврежденности наполнителя после консолидации можно провести по данным, представленным на рис. $3, b$. Из этого рисунка видно, что распределение довольно равномерное, среднее значение $I_{D} / I_{G}$ составляет $\sim 1.1$ и $\sim 0.9$ для наполнителей МУНТ и Al/МУНТ соответственно. Можно отметить увеличение на $15 \%$ отношения $I_{D} / I_{G}$ для консолидированных образцов, упрочненных МУНТ, по сравнению с таковым для некомпактного состояния, в то время как для составов, содержащих $\mathrm{Al} / \mathrm{MУНТ,} \mathrm{среднее} \mathrm{значение} I_{D} / I_{G}$ в компактном и некомпактном состояниях остается неизменным, т. е в процессе консолидации композиционного порошка, содержащего МУНТ, происходит дополнительное повреждение наполнителя, что связано с образованием кристаллической фазы $\mathrm{Al}_{4} \mathrm{C}_{3}$ при изотермической выдержке.
Далее было проведено сопоставление доли фазы $\mathrm{Al}_{4} \mathrm{C}_{3}$ и идеально гексагонального графита (рис. 3,c), т.е. сравнение отношения интенсивностей линий $I_{\mathrm{Al}_{4} \mathrm{C}_{3}}$ $\left(857 \mathrm{~cm}^{-1}\right)$ и $I_{G}$. Сравнительный анализ показывает, что для консолидированных образцов, упрочненных $\mathrm{Al} / \mathrm{MУНТ,} \mathrm{образование} \mathrm{фазы} \mathrm{Al}_{4} \mathrm{C}_{3}$ происходит в меньшей степени, чем для образцов, упрочненных МУНТ. Так, для композитов, упрочненных МУНТ, среднее значение $I_{\mathrm{Al}_{4} \mathrm{C}_{3}} / I_{G}$ составило 1.5 при стандартном отклонении $\mathrm{SD}=0.42$, в то время как для композитов, содержащих Al/MУНТ, данное соотношение равно 0.86 при $\mathrm{SD}=0.28$. Таким образом, для объемных композитов, упрочненных Al/MУНТ, образование фазы $\mathrm{Al}_{4} \mathrm{C}_{3}$ при изотермической выдержке происходит в меньшей степени, что должно положительно сказаться на пластичности материала. Бо́льшую долю фазы $\mathrm{Al}_{4} \mathrm{C}_{3}$ в композитах, упрочненных МУНТ, чем в образцах, содержащих Al/МУНТ, как следует из представленных выше данных, можно объяснить меньшей степенью повреждения Al/MУНТ, а следовательно, и меньшим количеством дефектных участков, являющихся локальными зонами образования $\mathrm{Al}_{4} \mathrm{C}_{3}$. Кроме того, частицы $\mathrm{Al}$ на по- 
верхности МУНТ-гибридного наполнителя уменьшают площадь контакта МУНТ с матричным материалом, выступая в роли интерфейса, что также локально ингибирует реакцию между матрицей и МУНТ.

Таким образом, суммарный анализ результатов показывает перспективность использования МУНТ-гибридных наноструктур в качестве упрочняющих наполнителей алюминиевых композитов, позволяющих снизить повреждаемость МУНТ, а также, что не менее важно, открывает возможность регулирования межфазной связи алюминиевая матрица-наполнитель за счет направленного создания интерфейса.

Исследование проведено при финансовой поддержке РФФИ в рамках проектов № 17-58-04048 Бел_мол_а, № 18-33-00776 мол_а и частично в рамках выполнения госзадания ИМХ РАН, тема 45.8 (рег. № AAAA-A16116122110057-9).

\section{Список литературы}

[1] Chen B., Shen J., Ye X., Jia L., Li S., Umeda J., Takahashi M., Kondoh K. // Acta Mater. 2017. V. 140. P. 317-325.

[2] Zhou W., Yamamoto G., Fan Y., Kwon H., Hashida T., Kawasaki A. // Carbon. 2016. V. 106. P. 37-47.

[3] Estili M., Kawasaki A. // Adv. Mater. 2010. V. 22. P. 607-610.

[4] Ci L., Ryu Z., Jin-Phillipp N.Y., Rühle M. // Acta Mater. 2006. V. 54. P. 5367-5375.

[5] Li H., Kang J., He C., Zhao N., Liang C., Li B. // Mater. Sci. Eng. A. 2013. V. 577. P. 120-124.

[6] Stein J., Lenczowski B., Fréty N., Anglaret E. // Carbon. 2012. V. 50. P. 2264-2272.

[7] Stein J., Lenczowski B., Anglaret E., Fréty N. // Carbon. 2014. V. 77. P. 44-52.

[8] Кремлев К.В., Объедков А.М., Семенов Н.М., Каверин Б.С., Кетков С.Ю., Гусев С.А., Юнин П.А., Елкин А.И., Аборкин А.В. // Письма в ЖТФ. 2018. Т. 44. В. 19. С. 24-31.

[9] Аборкин А.В., Алымов М.И., Киреев А.В., Елкин А.И., Собольков А.В. // Рос. нанотехнологии. 2017. № 7-8. С. $66-$ 70.

[10] Aborkin A.V., Sobol'kov A.V., Kireev A.V., Volochko A.T., Izobello A.Yu., Sachkova N.V., Sytschev A.E. // J. Phys.: Conf. Ser. 2018. V. 951. P. 012008.

[11] Аборкин А.В., Алымов М.И., Собольков А.В., Хорьков К.С., Бабин Д.М. // Металлы. 2018. № 4. С. 27-35. 